\title{
Investigation on mechanical properties of woven alovera/sisal/kenaf fibres and their hybrid composites
}

\author{
K PALANI KUMAR ${ }^{1, *}$ (D), A SHADRACH JEYA SEKARAN ${ }^{2}$ and K PITCHANDI ${ }^{3}$ \\ ${ }^{1}$ Department of Mechanical Engineering, Sri Sai Ram Institute of Technology, Chennai 600 044, India \\ ${ }^{2}$ Department of Mechanical Engineering, St. Peter's College of Engineering and Technology, Anna University, \\ Chennai 600 054, India \\ ${ }^{3}$ Department of Mechanical Engineering, Sri Venkateswara College of Engineering, Chennai 602 117, India
}

MS received 9 October 2015; accepted 30 May 2016

\begin{abstract}
The go-green concept results in multipoint focus towards materials made from nature; easily decomposable and recyclable polymeric materials and their composites along with natural fibres ignited the manufacturing sectors to go for higher altitudes in engineering industries. This is due to the health hazard and environmental problems faced in manufacturing and disposal of synthetic fibres. This study was undertaken to analyse the suitability of new natural fibre as an alternative reinforcement for composite materials. In this paper, tensile, flexural and impact test is made for the woven alovera and kenaf (AK), sisal and kenaf (SK), alovera, sisal and kenaf fibre hybrid epoxy composites (ASK). The composite laminates are made through a hand-layup process. The surface analysis is studied through scanning electron microscopy. From the investigation the SK hybrid composite shows good tensile property, AK hybrid composite shows better flexural property and the best impact strength is observed for ASK hybrid composite. The natural fibres slowly replace the synthetic fibres from its environmental impact, marching towards a revolution in engineering materials.
\end{abstract}

Keywords. Woven; natural fibres; hybrid; tensile; flexural; impact.

$\begin{array}{ll}\text { Abbreviations } \\ \text { AK } & \text { alovera and kenaf } \\ \text { SK } & \text { sisal and kenaf } \\ \text { ASK } & \text { alovera, sisal and kenaf } \\ \text { ASTM } & \text { American Society for Testing and Materials } \\ \text { DBA } & \text { data-based approximation } \\ \text { MPa } & \text { megapascal } \\ \text { NaOH } & \text { sodium hydroxide } \\ \text { RoHM } & \text { rule of hybrid mixture } \\ \text { SLS } & \text { sodium lauryl sulphate } \\ \text { SEM } & \text { scanning electron microscopy } \\ \text { J } & \text { joules } \\ \text { UTM } & \text { universal testing machine } \\ \text { kN } & \text { kilonewton } \\ \text { h } & \text { hours } \\ \text { mm } & \text { millimetre } \\ \text { min } & \text { minute }\end{array}$

\section{Introduction}

Natural fibres have enormous superior properties over synthetic fibres due to their inexpensiveness, low density, proven specific strength, better thermal insulation properties, nominal tool wear and easy renewability. Manufacturing natural

*Author for correspondence (palanikumar_k@yahoo.com) fibres has a huge impact in building a healthy environment; with higher fibre content for equivalent performance, its lower weight has greater effect in mileage improvement and emissions are drastically reduced, especially in autoapplications, compared with glass fibres [1]. Natural fibres extracted from banana, alovera, kenaf and sisal fibres are reviewed and the manufacturing process involved in fabricating these natural fibre composites with different resins is considered as an alternate strategy to eliminate plastic fibres as a core agent in composites [2]. The union between fibre and matrix as well as the characteristics of the fibre determines the properties of natural-fibre-reinforced composite. Further, these composites are improved by passing the fibre through various chemical processes before fabrication [3]. The structural properties of a sisal fibre will also get modified depending on the area in which it is cultivated, how it has grown, on the age of the plant and so on. Anyhow the experimental conditions and processing techniques such as fibre diameter, gauge length, strain rate, test temperature, fibre orientation and fibre-volume fraction also have a dominant role in affecting the mechanical and physical properties of sisal fibre [4]. Higher extensibility and fibre stiffness can be achieved through chemical and thermal treatment of sisal fibres; the mechanical property can be upgraded by increasing the bonding between the fibre bundles and matrix [5] On rinsing sisal fibres with $\mathrm{NaOH}$ solution, the reinforcement shows higher tensile strength and lower moisture absorption [6]. Hybrid composites of sisal/banana were tested for their 
tensile properties using the RoHM and it was found that the values are somewhat higher compared with the experimental values. This fact may be due to the presence of microvoids formed in the laminates during fabrication [7]. The scale of the fibre is also a reason for analysing the mechanical properties of sisal composite $v s$. the fibre content in the tensile and impact tests predicted by genetic algorithm and factorial design techniques [8]. Sisal fibre cement composite with the orientation of long aligned fibres as reinforcement that has undergone fatigue behaviour was studied for stress vs. cycles and stress-strain hysteresis behaviour. From the behaviour, no reduction in strength is observed, but Young's modulus is found to be reduced and growth of first crack strength is observed with higher rate of fatigue stress [9]. Naturally the sisal fibres have the characteristics of higher wear resistance compared with the matrix. Hence, the applicability of these composites in fibre board can be expanded [10]. Sisal/glass fibre composites show better tensile loading than jute/glass fibre composites and perform better for flexural loading [11]. The tensile, flexural and impact strength of randomly mixed fibre and woven form of banana/kenaf hybrid composite is enhanced by giving SLS treatment [12]. Water absorption test is carried out for kenaf/glass fibre reinforced with unsaturated polyester composite, by submerging the samples in rain water, distilled water and seawater. Deterioration in mechanical properties of kenaf fibre is observed due to the moisture content in the composites [13]. By using pultrusion and filament winding processes, kenaf fibre can be used as an choice to substitute synthetic fibres as reinforcement in composites because of its accessibility and ease of handling that have never been related to those of other natural fibres before
[14]. Alkali treatment shows difference in the cross-section of kenaf fibres when judged against the untreated fibres. This variation has a bigger impact in the progress of the tensile strength match-up to the strength values predicted by untreated fibre based on the DBA technique [15]. Fibre reference point, composition, uncovered surface area, permeability and hydrophilicity are the components that diminish the fracture toughness of long kenaf/woven glass hybrid composite due to the effect of water absorption [16]. Tensile, flexural and impact strength of woven banana and glass fibre epoxy composites is determined in relation to surroundings to handle artificial fibres [17]. Mechanical properties are experimentally studied for alkali-treated kenaf-fibrereinforced polyester composite processed by vacuum infusion technique and the properties are found to be amplified [18]. Bumper beams and front-end modules prepared with hybrid kenaf/glass-reinforced material might be utilized in auto-industries by developing the impact properties as well as by diminishing the thickness and beam curvature, and strengthening the ribs [19]. In this research work an effort has been made to study the mechanical properties of hybrid woven alovera/sisal/kenaf-fibre-reinforced epoxy composites along with scanning electron microscopy (SEM) analysis. Performance of the individual composites is summarized.

\section{Experimental}

\subsection{Materials}

The composite material used in this research is fabricated using natural fibres such as alovera, sisal and kenaf in woven form, which are shown in figure 1. The natural fibres
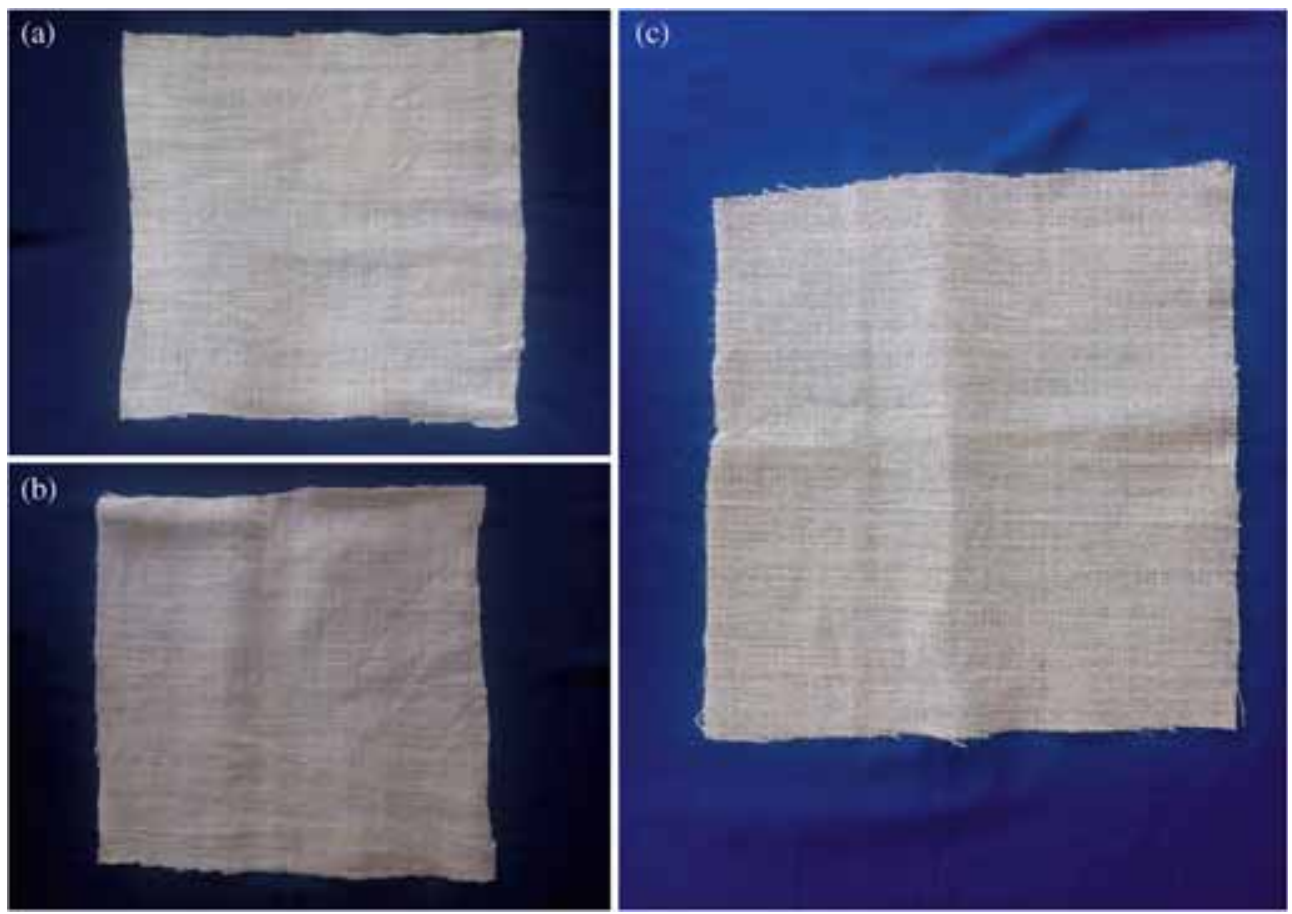

Figure 1. (a) Alovera, (b) sisal and (c) kenaf woven natural fibres. 
were collected from Anakaputhur Jute Weaver Association, Chennai, India. Matrix material selected is epoxy resin grade B-11 (3101) and hardener grade K-6 (5205) as binder for the resin. Manufacturing process of the composites was carried out at Creative Composites, Chennai, India. Mechanical experiments were carried out at Omega Inspection and Analytical Laboratory, Chennai, India. From the rule of mixture it is predicted that the natural woven fibre fabric used in this investigation is $65 \%$ and the epoxy resin used is $35 \%$. The pattern of woven fabric is of plain weave type and it offers high fabric integrity and dimensional stability.

\subsection{Composite preparation}

Several methods exist for the fabrication of composites; for example, hand layup, compression molding, resin transfer molding, filament winding, pultrusion and vacuum molding are the familiar processes. In this investigation the composite laminates were prepared by hand layup procedure. It is one of the easiest and simplest techniques and involves mixture of resin and fibres in different forms. Keeping the woven fibre mats in a standard size mold, resin is applied with a brush on the exterior layers of the fibre mat immediately followed by forcing the rollers. Air voids are removed based
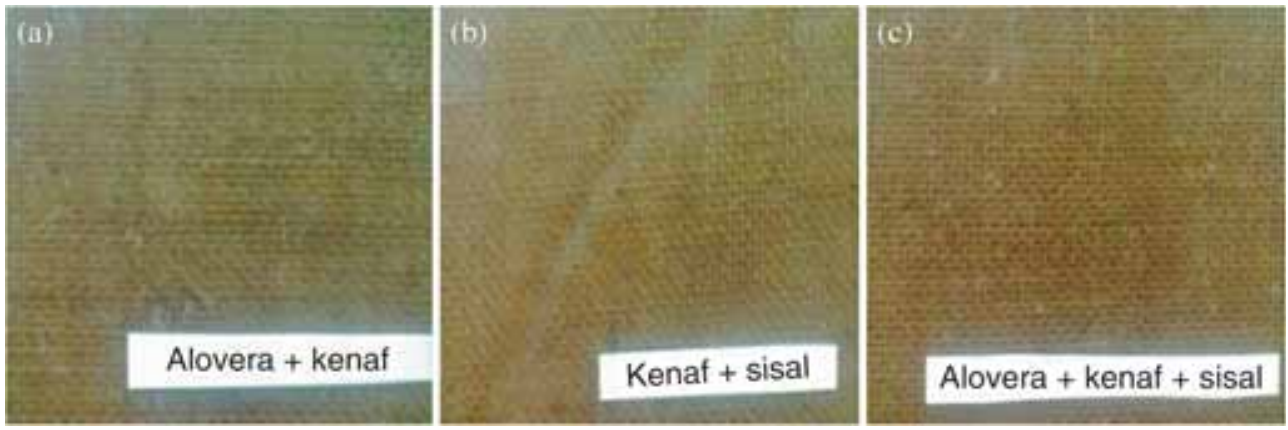

Figure 2. Hybrid (a) AK, (b) SK and (c) ASK composite laminates.
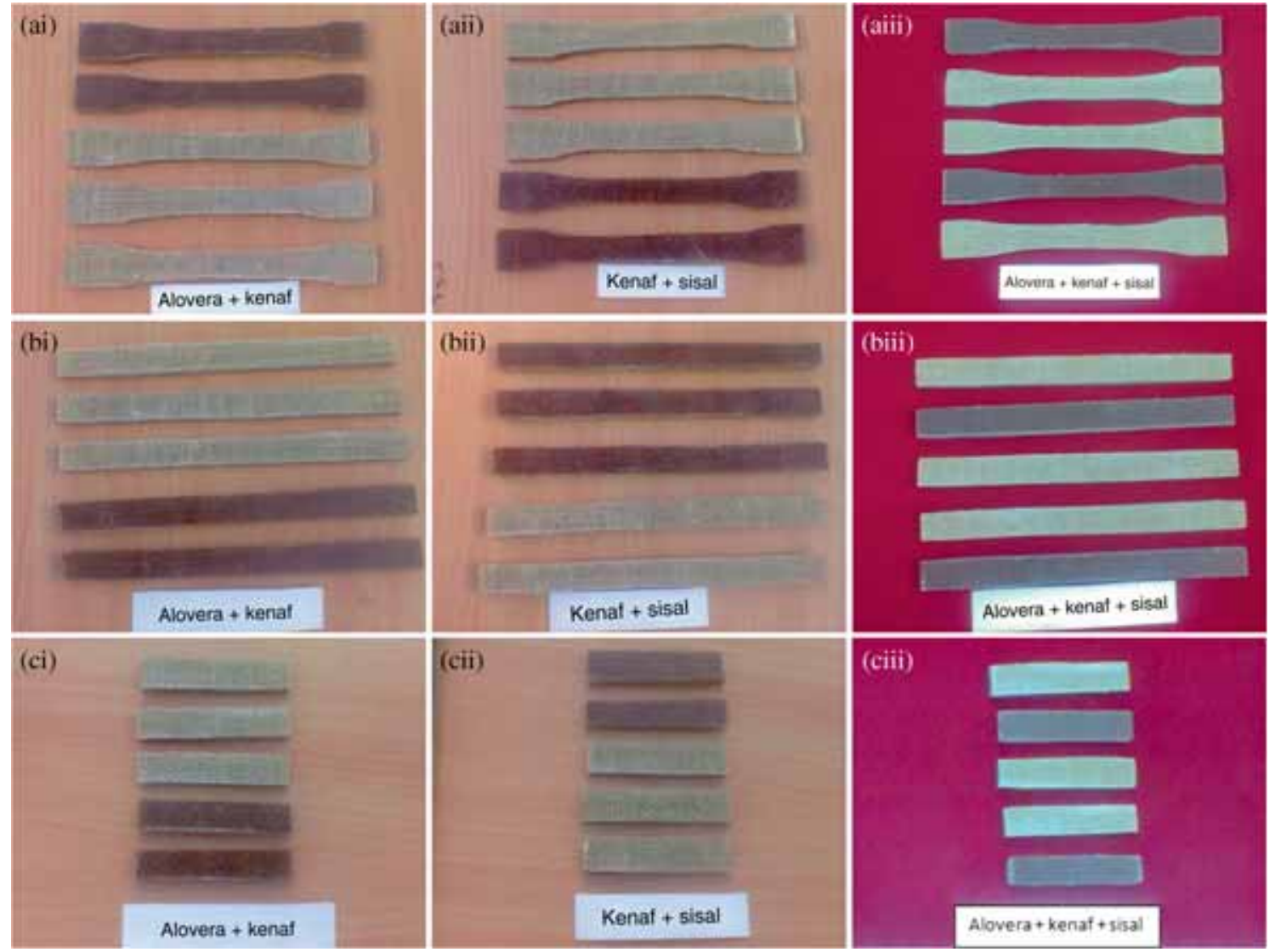

Figure 3. (a) Tensile, (b) flexural and (c) impact specimens of woven alovera, sisal and kenaf hybrid composite. 
on the pressure applied by the operator's hand and uniform movement of rollers should be maintained. Desired thickness of the composite laminate is obtained by adding the mat layers and applying the resin sequentially. The main advantage of this technique is that in less time large and complicated parts can be fabricated. Because of the simple equipment and tools the manufacturing cost is far less compared with the other techniques. In this study woven

(a)

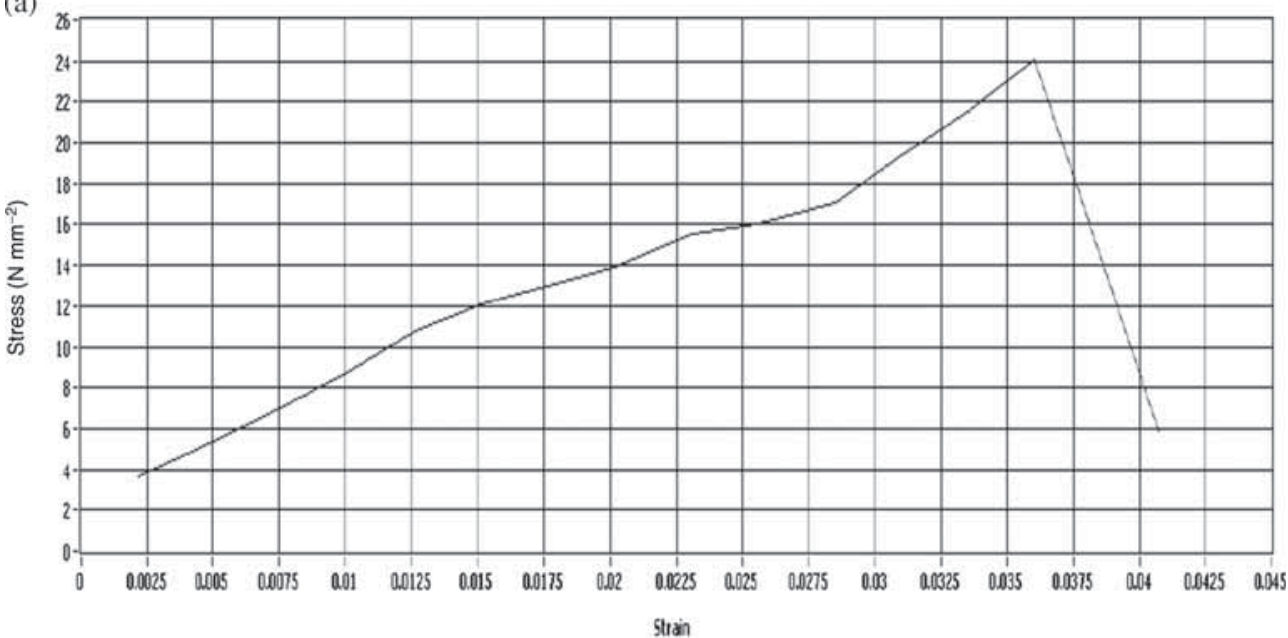

(b)
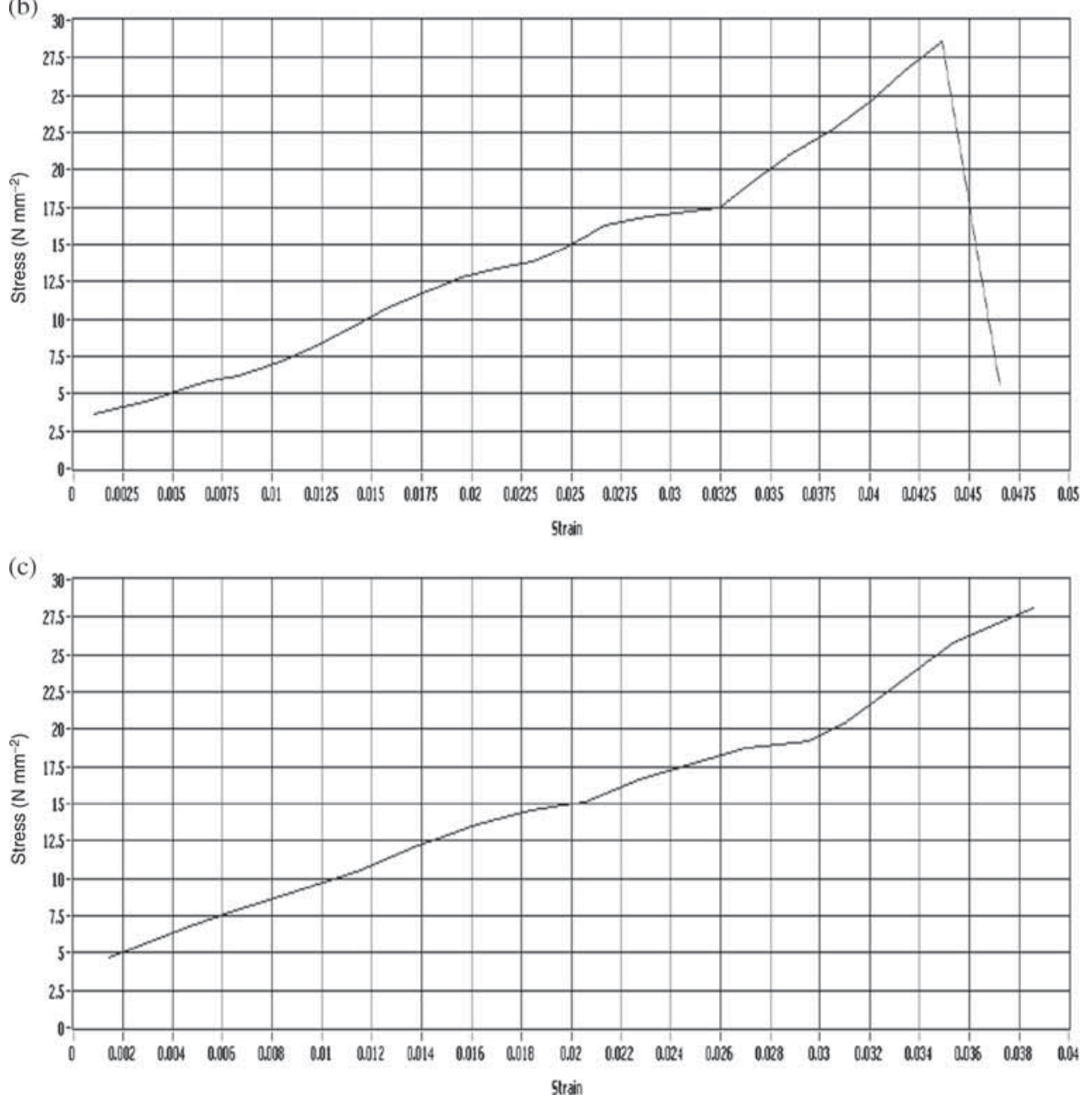

Figure 4. Stress-strain model graph produced from the machine for tensile investigation of woven (a) AK, (b) SK and (c) ASK hybrid composites. 
alovera/sisal/kenaf fibres in mat form were reinforced separately into epoxy resin and the related hardener was merged in a ratio of 10:1 by weight as suggested. The mixing of resin and hardener is done very carefully with proper stirring to dissolve the resin and the hardener in the medium. Finally the fabricated composite is removed from the mold, after curing. The above-mentioned procedure is followed in preparing the AK composite. The woven alovera fibre mat measures

(a)

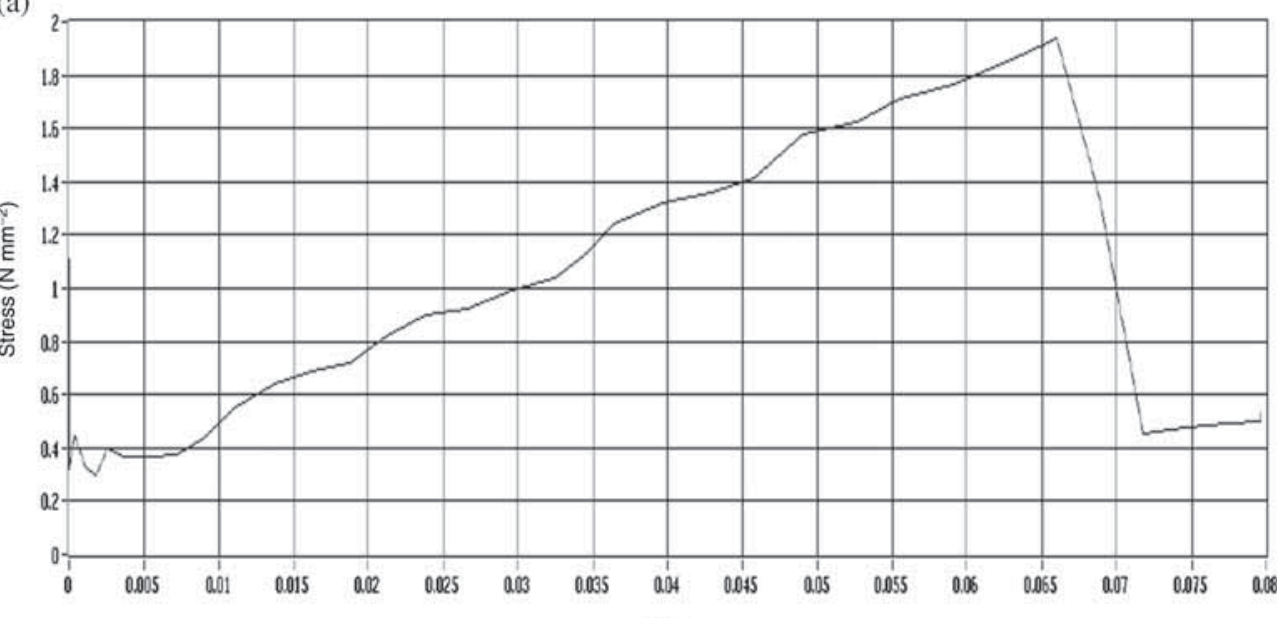

(b)
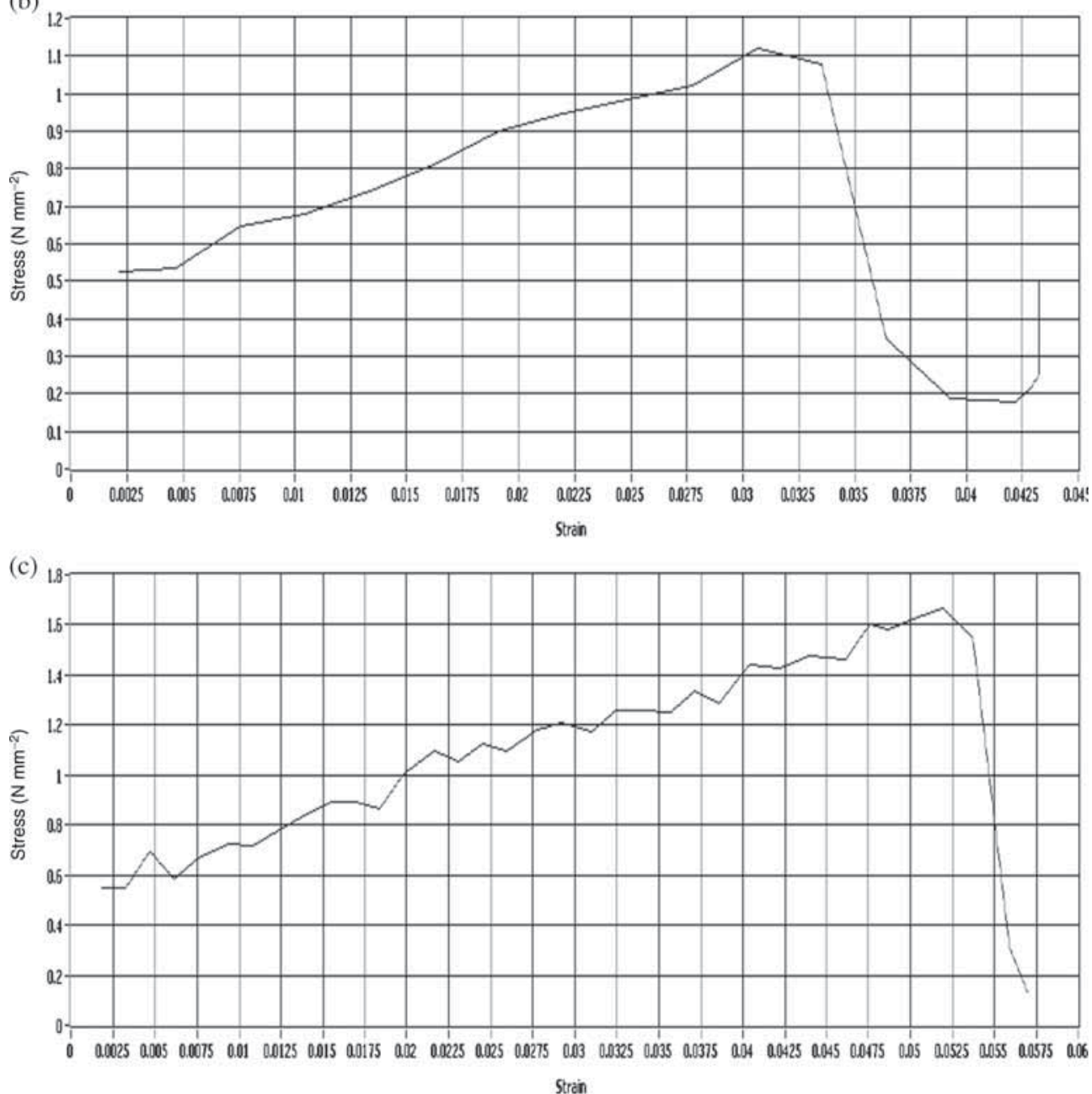

Figure 5. Stress-strain model graph produced from the machine for flexural investigation of woven (a) AK, (b) SK and (c) ASK hybrid composites. 
$300 \times 300 \mathrm{~mm}$ and $0.7 \mathrm{~mm}$ in thickness; it is kept at $0^{\circ}$ orientation on the epoxy resin that has been coated inside the mold as the first layer for the laminates. Later epoxy resin is coated on the entire surface on the mat, which has been kept inside the mold. At this stage the woven kenaf fibre mat measures the same dimensions of $300 \times 300 \mathrm{~mm}$ and $0.7 \mathrm{~mm}$ in thickness; it is kept at $0^{\circ}$ orientation as a second layer inside the mold. Then epoxy resin is applied and fills over the entire surface of the fibre mat. In similar way alternate fibre mats of alovera and kenaf are placed in between each resin coatings. The process is repeated until a thickness of $3.2 \mathrm{~mm}$ is obtained in the laminates. Nearly four layers have been used in preparing the laminates. The air space generated among the layers during fabrication is detached out by using the rollers. Then the composite laminate is squeezed together for a setting period of $24 \mathrm{~h}$. Thus the AK hybrid composite laminate prepared by the hand layup technique is presented in figure 2a. Similarly SK hybrid composite laminate is prepared by the same procedure adapted for the preparation of AK hybrid composite. Here, woven sisal and kenaf fibres with the same dimensions mentioned above are kept as alternate layers in preparing the composite until the desired thickness of $3.2 \mathrm{~mm}$ is obtained. The fabricated sisal and kenaf hybrid composite laminate is presented in figure $2 \mathrm{~b}$. Likewise, the ASK hybrid composite is also fabricated by the same methodology followed with respect to same measurements by the above-mentioned procedure. Here woven alovera fibre is kept as a first layer and woven sisal fibre as a second layer. The remaining two layers are reinforced by woven kenaf fibre. The prepared alovera, sisal and kenaf hybrid composite laminate is presented in figure 2c. The three hybrid composite laminates AK, SK and ASK experimented in this study are prepared in a uniform manner to determine their mechanical properties as well as surface morphology after testing.

\subsection{Specimen preparation}

From the prepared AK, SK and ASK woven composite laminates, the dimensions are marked with the help of the template made according to ASTM D638 standard for tensile testing, ASTM standard D790 for flexural testing and ASTM D256 customary for impact testing [20-25]. Using a saw cutter five specimens in all the three hybrid composite laminates are prepared. The edge of the specimen is smoothened using a file and emery sheet to get a smooth surface; also the extruded fibres on the cut area is removed. This is done to get a fracture exactly at the middle of the specimen while doing tensile test. The prepared specimens from the AK, SK and ASK hybrid composite laminates that undergo mechanical testing are shown in figure 3.

\subsection{Mechanical properties}

Performance and behaviour of any material are represented by its mechanical phenomenon, such as tensile, flexural and impact loadings. Here performance of the three hybrid composites AK, SK and ASK is investigated. This distinctiveness is very essential to predict material capacity and durability over various load settings. The mechanical properties of the hybrid composites vary based on the fibre form, its orientation, the polymer used and also based on other external factors such as sample preparation, internal and external surface defects, testing temperature and nature of the material.

The tensile test is executed on a UTM at a speed of $2.5 \mathrm{~mm}$ $\min ^{-1}$. The standard followed for tensile testing is ASTM D638. Three different types of specimens were prepared from woven alovera, sisal and kenaf hybrid composites. The tensile test is done by clamping the specimen in the required fixture of the machine and load is given, till the sample breaks. The stress-strain graph generated from the machine for all the three hybrid composites AK, SK and ASK is presented in figure $4 \mathrm{a}-\mathrm{c}$. The maximum tensile stress of 28.59 $\mathrm{N} \mathrm{mm}^{-2}$ is obtained for SK hybrid composite under a tensile load of $1.66 \mathrm{kN}$. AK hybrid composite is also found to have a closer value of $28.15 \mathrm{~N} \mathrm{~mm}^{-2}$.

The flexural experiment is done by means of the UTM according to ASTM standard D790. Three different types of samples were made ready as per the above standard from woven alovera, sisal and kenaf hybrid composites. The flexural test is done by clamping the specimen in the required fixture of the machine and load is given. The deflection of the specimen is measured under a compressive load until the specimen breaks or cracks. The stress-strain graph generated from the machine for all the three woven composites during the test is presented in figure $5 \mathrm{a}-\mathrm{c}$.

For impact testing, the specimens were prepared from woven alovera, sisal and kenaf hybrid composites. An impact test is a test for determining the energy absorbed in

Table 1. Mechanical properties of tested composites.

\begin{tabular}{lccc}
\hline Samples & $\begin{array}{c}\text { Tensile load } \\
(\mathrm{kN})\end{array}$ & $\begin{array}{c}\text { Flexural load } \\
(\mathrm{kN})\end{array}$ & $\begin{array}{c}\text { Impact load } \\
(\mathrm{J})\end{array}$ \\
\hline AK hybrid composite & 1.35 & 0.10 & 6 \\
SK hybrid composite & 1.66 & 0.06 & 6.1 \\
ASK hybrid composite & 1.46 & 0.09 & 6.2 \\
\hline
\end{tabular}

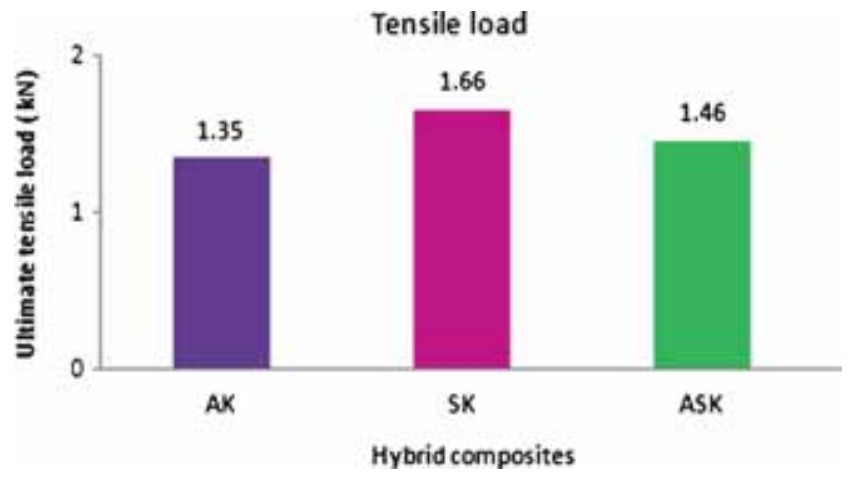

Figure 6. Tensile load comparison of hybrid composites. 
fracturing a test piece at high velocity. The impact power of the composite samples is examined with an Izod impact tester. The specimens are prepared according to the ASTM D256 standard.

\section{Results and discussion}

Natural fibres are making a dynamic impact at present in this modern era and they reduce the environment pollution. They are superior alternatives to glass fibres in composites. The major reason for replacing the glass fibre with that of natural fibres is that the production of natural fibres has less environmental impact compared with the glass fibre

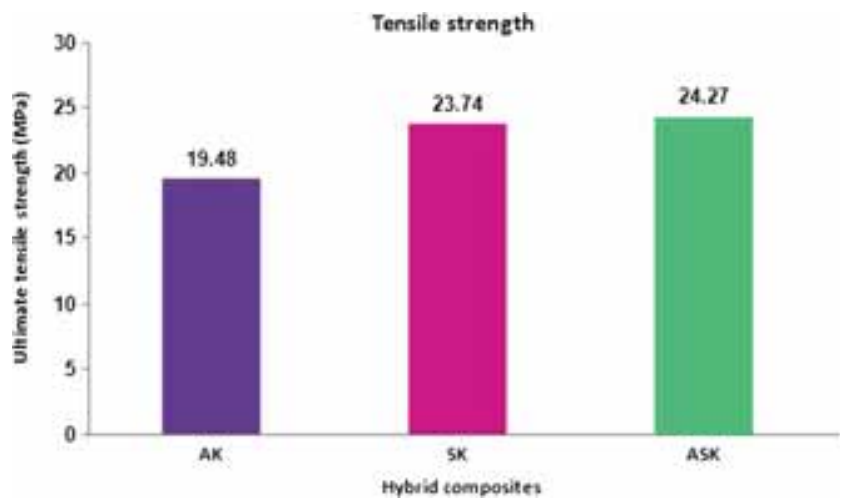

Figure 7. Tensile strength comparison of hybrid composites.

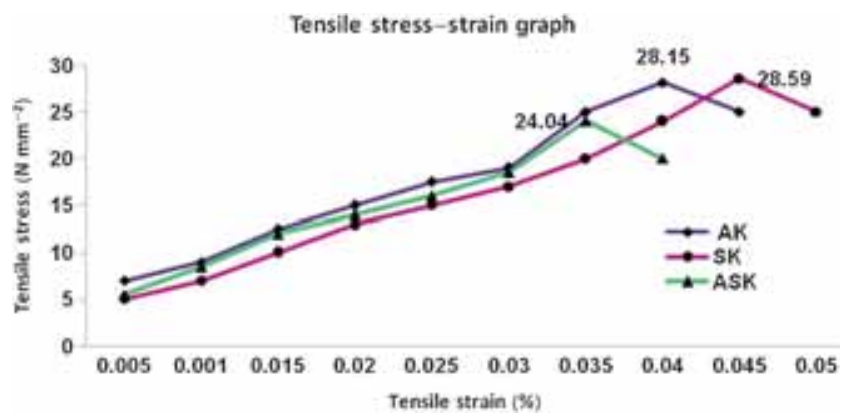

Figure 8. Tensile stress-strain of hybrid composites.

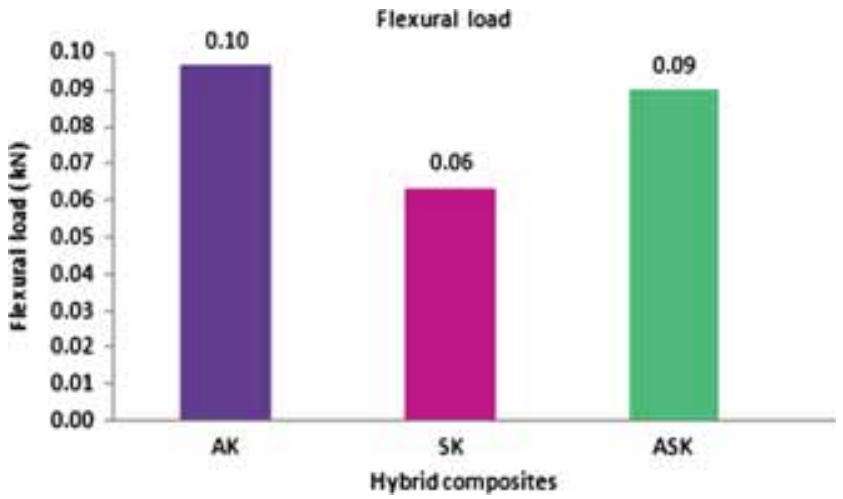

Figure 9. Flexural load comparison of hybrid composites. production. Jeyanthi and Janci Rani [19] discussed that, during this decade natural fibres are acting as a strengthening agent in polymer composites for varieties of applications in automotive industries, structures and consumer goods. This study is used to examine the mechanical properties and its surface morphologies using SEM for natural woven alovera, sisal and kenaf natural-fibre-reinforced epoxy hybrid composites.

\subsection{Mechanical properties}

The tensile, flexural and impact test results for all the three hybrid composite samples and their summative values are

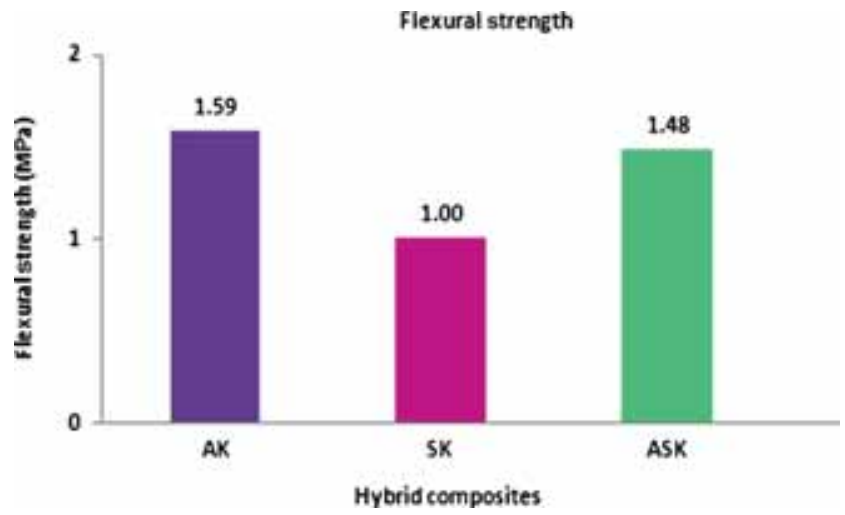

Figure 10. Flexural strength comparison of hybrid composites.

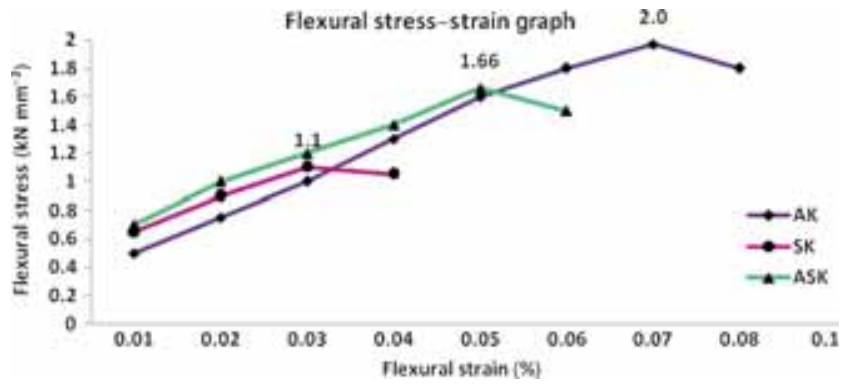

Figure 11. Flexural stress-strain of hybrid composites.

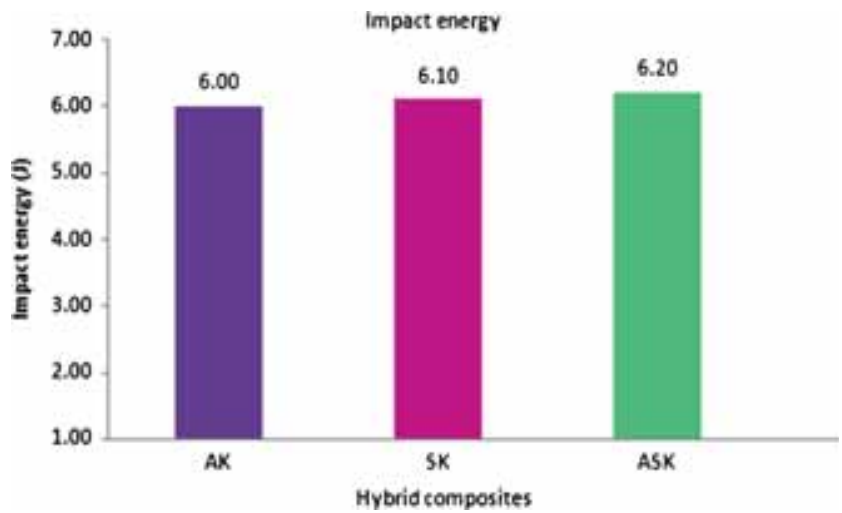

Figure 12. Impact strength comparison of hybrid composites. 
presented in table 1 . The tensile strength for the hybrid composites tested depends on the bonding among the fibres and the matrix. Investigation reveals that the interface between fibre and matrix has significant effect on mechanical properties. The comparative tensile load of the woven hybrid composite samples of AK, SK and ASK is presented in figure 6. The outcome indicates that the upper limit tensile load of $1.66 \mathrm{kN}$ is observed for SK hybrid composite compared with the AK and ASK hybrid composites. The comparative ultimate tensile strength of the three experimented hybrid composite samples tested is presented in figure 7. The maximum stress before fracture, under applied and varying load, in tension is known to be the ultimate tensile strength. The outcome shows that the highest ultimate tensile strength of 24.27 $\mathrm{MPa}$ is found for the ASK hybrid composite, compared with the AK and SK hybrid composites. Comparison of tensile stress with respect to the strain for the three experimented hybrid composite samples is given in figure 8 . The literatures indicated that the tensile properties are enhanced due to hybridization of fibres.

The outcome indicated that the SK hybrid composite gives higher stress of $28.59 \mathrm{~N} \mathrm{~mm}^{-2}$, and the AK hybrid composite also shows more or less nearly equivalent higher stress of $28.15 \mathrm{~N} \mathrm{~mm}^{-2}$. From the present investigation for tensile
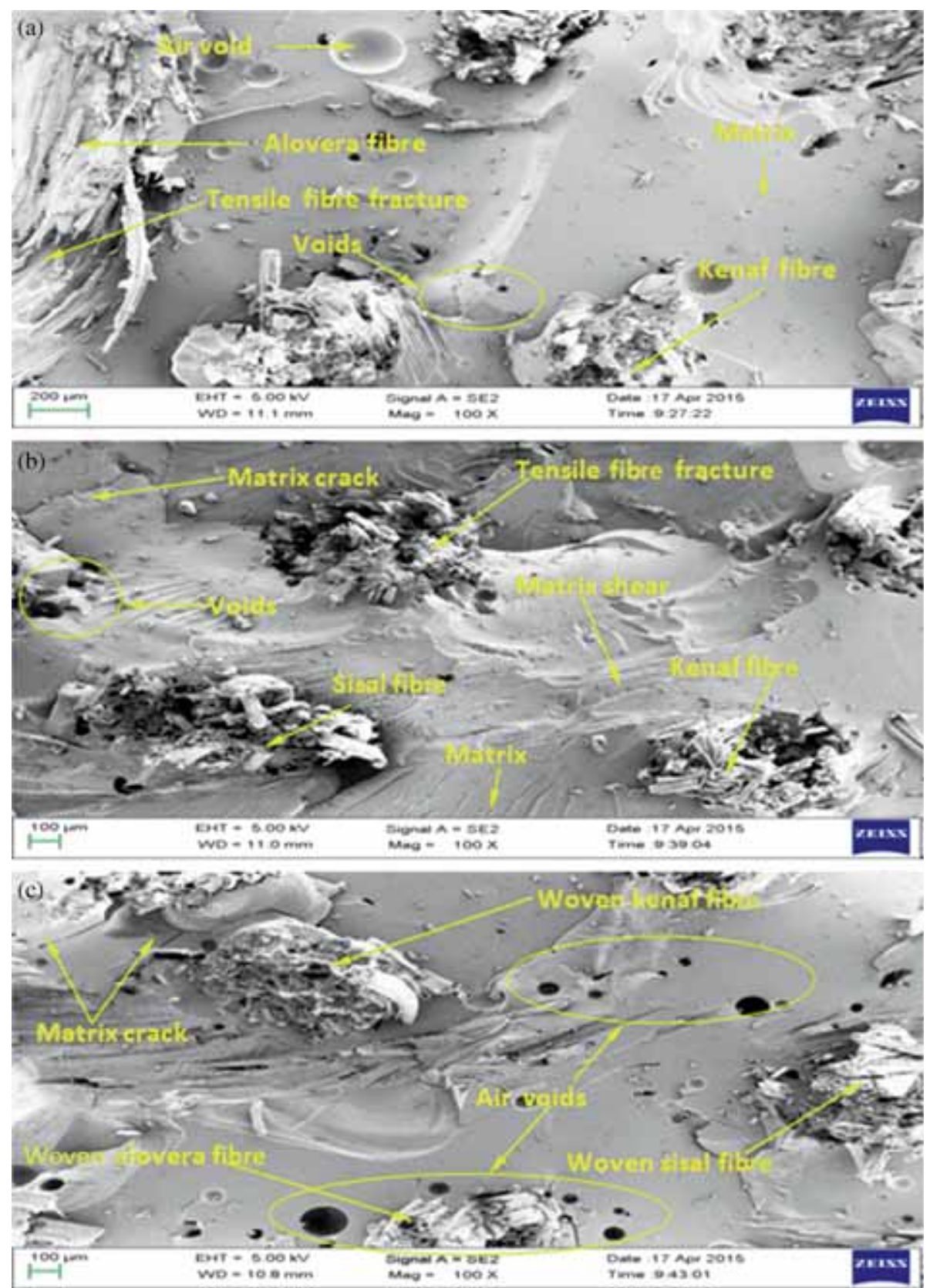

Figure 13. SEM image of (a) AK, (b) SK and (c) ASK hybrid composites that underwent tensile test at magnification factor $100 \times$. 
properties of AK, SK and ASK hybrid composite carried out the SK hybrid composite shows good tensile property. Venkateshwaran et al [7] predicted the tensile characteristics of natural hybrid composites for banana and sisal with random oriented fibres. Hence in this investigation woven form of fibre is considered, so tensile strength values are found to be increased. Also, Thiruchitrambalam et al [12] examined the improvement of tensile characteristics of woven banana and kenaf hybrid polyester composite due to sodium lauryl sulphate treatment of fibres. In this investigation epoxy resin is used and fibres are untreated, so the tensile strength values are found to be less. Therefore in this investigation it is found that the tensile strength values can be improved if the fibres are treated before preparing composites. The flexural characteristics of the AK, AS and ASK hybrid natural composite samples tested in the UTM with three-point bending fixtures and their relative results for flexural load is given in figure 9. It is observed that the flexural load withstanding ability of AK hybrid composite is superior to the other two AS and ASK hybrid composite. Comparative ultimate flexural strength of all the three woven natural fibre hybrid composite samples tested is given in figure 10. The output shows that the highest ultimate flexural strength of 1.59 MPa is observed for AK hybrid composite compared with
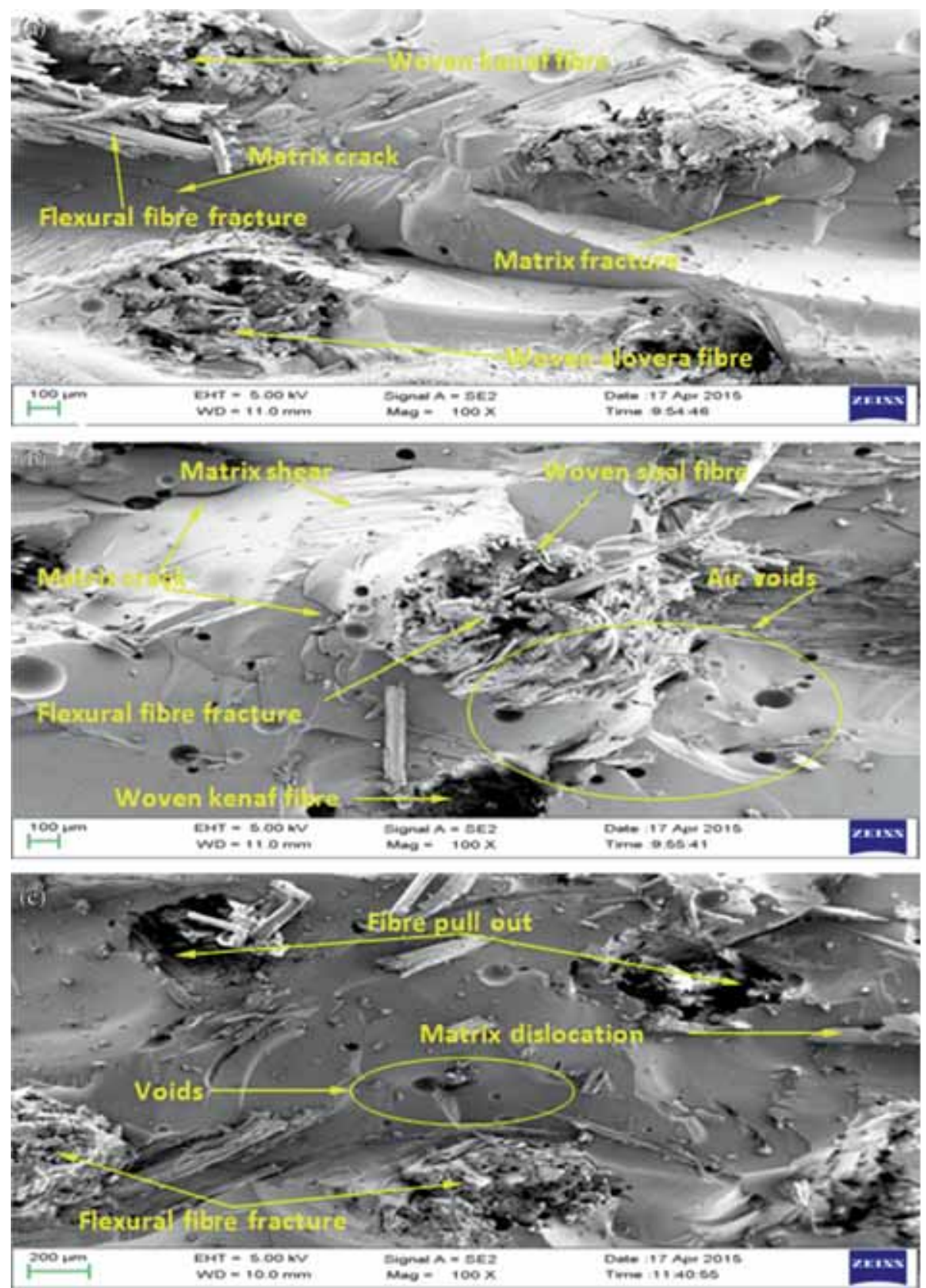

Figure 14. SEM image of (a) AK, (b) SK and (c) ASK hybrid composites that underwent flexural test at magnification factor $100 \times$. 
the AS and ASK hybrid composites. The flexural stress with respect to the strain for the three natural hybrid composite samples is given in figure 11 . The outcome pointed out that the AK hybrid composite withstands higher flexural stress under three-point-loading. Ramesh et al [11] discussed that between sisal hybridized with glass and jute hybridized with glass fibre, jute/glass shows better flexural properties. Here in this investigation it is observed that the AK hybrid shows very good flexural load and strength. The impact strength of the AK, AS and ASK natural hybrid composite samples are tested by the Izod impact tester and the comparative results are presented in figure 12. The ASK hybrid composite is found to have the highest impact energy of 6.2 J. From the mechanical testing carried out the SK hybrid composite shows good tensile properties. The AK hybrid composite shows better flexural properties. Finally the ASK hybrid composite is observed to have good impact strength. From a review of literature other authors have tried a mixture of natural fibres with synthetic fibres and found that it has good ultimate tensile strength. However, in this investigation, the biodegradable material, only natural fibres alone are considered for preparing the hybrid composites. A new natural fibre alovera is experimented and found to have good flexural property due to hybridization.
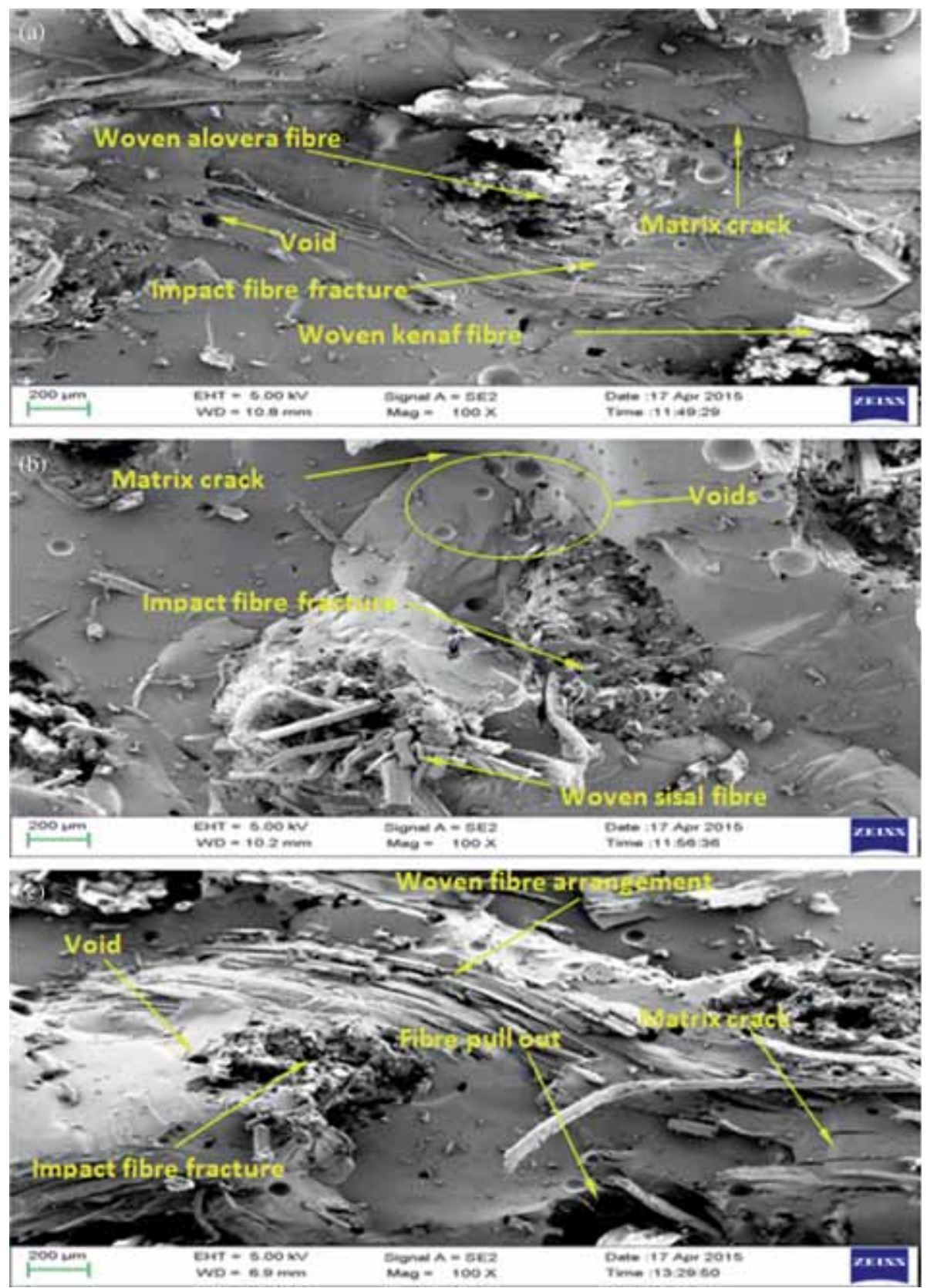

Figure 15. SEM image of (a) AK, (b) SK and (c) ASK hybrid composite that underwent impact test at magnification factor $100 \times$. 


\subsection{Scanning electron microscopy}

SEM is used to examine microscopic detail of specimens that have initially been viewed in an optical microscope but subsequently found to require SEM examination in order to provide information not available from the optical microscope. The SEM pictures were taken from a Carl Zeiss SUPRA 55 FESEM that has a resolution of $0.8 \mathrm{~nm}$ and the enlargement factor varies from $100 \times$ to $1000 \mathrm{k} \times$. Sample specimens prepared from the tested samples of tensile, flexural and impact AK, SK and ASK hybrid composites from which the SEM images have been taken are presented in figures 13-15. It is clearly seen from the SEM images that the surface failure is mainly due to the fibre and its fracture, fibre pullout, debonding and matrix fracture as well as dislocation of fibres. The poor bonding of fibre in matrix and many voids present in the composite lead to premature surface failure in the mechanical testings carried out. Humidity aging is also the main cause of failure because of the matrix exposed to atmosphere. Other factors such as matrix plasticization and embrittlement are found to be clear and good, in some regions where uniform pressure is maintained in rollers prepared the composite. It also affects the mechanical properties and dimensional stability. The SEM images of AK, SK and ASK tensile fractured specimens are shown in figure 13a-c. The SEM images show improper adhesion between the fibres and resin in the fractured samples. This is due to the many number of voids present inside the matrix and the formation of cavities. Hence the samples fail in fracture well in advance. The ductile type of fracture is observed and the fracture is caused due to the presence of microscopic defects such as voids and cracks in the matrix, which degrade the tensile strength of the composites. Based on the study of the surface morphology through SEM it can be said that the hand layup technique carried out without voids will improve the tensile properties. In figure $14 \mathrm{a}-\mathrm{c}$, flexural fractured specimen SEM images are shown. Fibre pullouts are noted and ductile fracture takes place where there is a weak interface between the matrix and fibre. Matrix crack is also observed and this is due to improper mixing of the resin with the hardener during the layup process. These factors are observed during surface studies on flexural fractured specimens and are the causes for deterioration of flexural strength in the composites. The SEM images of AK, AS and ASK of impact samples are presented in figure 15a-c. The shear and cleavage mode of fracture is observed and varying the proportion of matrix and fibre may upgrade the impact strength of the composites. Adhesion at the interface between the matrix and fibre plays a main role in shaping the mechanical characteristics of the composites. The surface morphology indicates that the formation of voids and cavities in all the samples is responsible for reduction in tensile, flexural and impact strength of these hybrid composites. Hence in this investigation woven fibre mats are used in preparing the composites; uniform distribution of resin around the fibres and air lock are the major causes as observed in micrographs.

\section{Conclusion}

The natural fibre slowly replaces the synthetic fibres from its environmental impact, marching towards a new era in engineering materials. In this study the tensile, flexural and impact strength behaviour of natural hybrid composites AK, SK and ASK is studied. SEM analysis has also been carried out for the tested specimens. Based on the outcome obtained during the investigation the conclusions are as follows:

(1) A new natural fibre alovera in woven form is experimented with hybridization of sisal and kenaf fibres.

(2) The results indicated that sisal-kenaf combination gives good tensile properties by giving tensile stress of $28.59 \mathrm{~N} \mathrm{~mm}^{-2}$ and $1.66 \mathrm{kN}$ of tensile load.

(3) The AK hybrid composite shows better flexural properties by withstanding a maximum of $0.1 \mathrm{kN}$ and it can be utilized for structural applications.

(4) Good impact strength is observed for the ASK hybrid composite because of the integration of three different fibres in the composite.

(5) SEM micrographs are used for analysing the surface of all-hybrid composites used and they indicate the fractured surfaces and also show the internal defects such as voids, micro-cracks, etc.

Here mainly new alovera fibre is used and it is well known for its medicinal values. Due to the forecast of the future demands for an environment friendly material, more and more deeper and crucial investigations are required in this area of natural fibre composites for product commercialization. Affordable manufacturing sectors and processes have to be developed in large scale.

\section{References}

[1] Joshi S V, Drzal L T, Mohanty A K and Arora S 2004 Composites: Part A 35371

[2] Palani Kumar K and Shadrach Jeya Sekaran A 2014 J. Reinf. Plast. Compos. 331879

[3] Ramakrishna Malkapuram, Vivek Kumar and Yuvraj Singh Negi 2009 J. Reinf. Plast. Compos. 281169

[4] Yan Li, Yiu-Wing Mai and Lin Ye 2000 Compos. Sci. Technol. 602037

[5] Rong M Z et al 2001 Compos. Sci. Technol. 611437

[6] Thais H D Sydenstricker, Sandro Mochnaz and Sandro C Amico 2003 Polym. Test. 22375

[7] Venkateshwaran N, Elayaperumal A and Sathiya G K 2012 Composites: Part B $\mathbf{4 3} 793$

[8] Velumani S, Navaneethakrishnan P, Jayabal S and Robinson Smart D S 2013 Bull. Mater. Sci. 36575

[9] Flávio de Andrade Silva, Barzin Mobasher and Romildo Dias Toledo Filho 2010 Mater. Sci. Eng. A 5275507

[10] Zhong J B, Lv J and Wei C 2007 eXPRESS Polym. Lett. 1681

[11] Ramesh M, Palanikumar K and Hemachandra Reddy K 2013 Procedia Eng. 51745 
[12] Thiruchitrambalam M, Alavudeen A, Athijayamani A, Venkateshwaran N and Elaya Perumal A 2009 Mater. Phys. Mech. 8165

[13] Ghani M A A, Salleh Z, Koay Mei Hyie, Berhan M N, Taib Y M D and Bakri M A I 2012 Procedia Eng. 411654

[14] Akil H M, Omar M F, Mazuki A A M, Safiee S, Ishak Z A M and Abu Bakar A 2011 Mater. Des. 324107

[15] Nitta Y, Goda K, Noda J and Lee W-Il 2013 Composites: Part A 49132

[16] Salleh Z, Taib Y M, Koay Mei Hyie, Mihat M, Berhan M N and Ghani M A A 2012 Procedia Eng. 411667

[17] Shadrach Jeya Sekaran A, Palani kumar K, Pitchandi K and Karunamoorthy L 2015 Appl. Mech. Mater. 766-767 110

[18] Mohd Yuhazri Y, Phongsakorn P T, Haeryip Sihombing, Jeefferie A R, Puvanasvaran Perumal, Kamarul A M and Kannan Rassiah 2011 Int. J. Eng. Technol. IJET-IJENS 11106
[19] Jeyanthi S and Janci Rani J 2012 J. Appl. Sci. Eng. 15275

[20] Srinivasan V S, Rajendra Boopathy S, Sangeetha D and Vijaya Ramnath B 2014 Mater. Des. 60620

[21] Naresh Kr Sharma and Kumar V 2008 J. Reinf. Plast. Compos. 32525

[22] Venkateshwaran N, ElayaPerumal A, Alavudeen A and Thiruchitrambalam M 2011 Mater. Des. 324017

[23] ASTM D638-03 2002 Standard test method for testing tensile properties of plastics, ASTM International, United States

[24] ASTM D790-07 2003 Standard tests method for testing flexural properties of unreinforced and reinforced plastics and electrical insulating material, ASTM International, United States

[25] ASTM D256-06a 2006 Standard test method for determining izod pendulum impact resistance of plastics, ASTM International, United States 